\title{
AS SINGULARIDADES DO ESPAÇO URBANO E SUAS IMPLICAÇÕES NAS PRÁTICAS TERRITORIAIS DO ENTORNO DE MAPUTO/MOZ
}

\author{
THE SINGULARITIES OF URBAN SPACE AND THEIR IMPLICATIONS IN TERRITORIAL PRACTICES IN THE MAPUTO / \\ MOZ SURROUNDINGS
}

\section{RESUMO}

Buscamos apresentar neste artigo o relato de um recorte dos olhares obtidos durante experiência de pesquisa realizada em Maputo, capital de Moçambique, de abril a maio de 2015. No caso do presente olhar, destacamos a análise acerca das singularidades do espaço urbano e suas implicações nas práticas territoriais do Vale do Infulene e Distrito de Marracuene, no entorno de Maputo/MOZ; e do entorno de Xai-Xai, capital da Província de Gaza; além da praia de Chidenguele/Xai-Xai. No deslindar da pesquisa percebemos histórias singulares, com maior destaque às das mulheres. Histórias estas vividas no contexto sempre de acontecimentos marcantes da sociedade moçambicana, tal como o processo de independência nacional (1975) e, como uma de suas consequências, a incorporação do aproveitamento do solo / uso tradicional da terra; além das profundas marcas deixada pela Guerra Civil (1976-1992). As práticas produtivas alternativas efetivadas pelas comunidades, na construção dos territórios, podem ser entendidas como coexistência do "avanço" da modernização capitalista e manutenção de práticas tradicionais, que ressignificam os espaços rural e urbano e se exprimem numa paisagem urbana com fortíssimas imbricações rurais.

Palavras-chave: Moçambique. Maputo. Mulheres.Urbano e Rural.

\section{ABSTRACT}

We seek to present in the article the account of some looks obtained during a research experience carried out in Maputo, capital of Mozambique, from April to May 2015. In the case of the present look, we highlight the analysis about the singularities of the urban space and its implications in the territorial practices of Vale do Infulene and Marracuene District, around Maputo / MOZ; and around XaiXai, capital of Gaza Province; besides the Chidenguele / Xai-Xai beach. As we unraveled the research, we noticed singular stories, with greater emphasis on those of women. Stories that are lived in the context of important events in Mozambican society, such as the process of national independence (1975) and, as one of its consequences, the incorporation of the use of soil / traditional land use; beyond the deep marks left by the Civil War (1976-1992). The alternative productive practices carried out by the communities, in the construction of the territories, can be understood as coexistence of the "advance" of capitalist modernization and maintenance of traditional practices, which resignify the rural and urban spaces and are expressed in an urban landscape with strong rural overlays.

Keywords: Mozambique.Maputo. Women. Urban and Rural.

\author{
Bruno Ferreira Campos ${ }^{a}$ \\ Cláudia Delboni ${ }^{\mathrm{a}}$ \\ a Universidade Federal da Grande \\ Dourados (UFGD), Dourados, MS, Brasil
}

DOI: $10.12957 /$ geouerj.2020.53710

Correpondência: brunofcampos@hotmail.com

Recebido em: 24 jun2019

Revisado em: 16 mar 2020

Aceito em: 09 mai 2020 


\section{INTRODUÇÃO}

Neste artigo, apresentaremos o relato de parte da experiência de pesquisa realizada no período de 30 dias, na cidade de Maputo, Moçambique, com enfoque voltado, mais especificamente para o Distrito de Marracuene, dentre outros locais de tipologia semelhante (forte presença das práticas agrárias/agrícolas).

O objetivo da atividade de pesquisa foi compreender o processo de constituição do território rural em Moçambique, especificamente no Distrito de Marracuene e promover a construção de conhecimentos pautada na socialização de saberes e fazeres entre docentes e discentes dos grupos de pesquisas do Brasil e de Moçambique participantes do projeto; Contribuir com a reflexão sobre estratégias produtivas possíveis para superar situações de miséria/vulnerabilidades através de relatos e apresentações de experiências desenvolvidas no Brasil; Conhecer as práticas produtivas alternativas efetivadas pelas comunidades do Distrito de Marracuene e promover o diálogo entre as experiências dos Grupos de Pesquisa participantes da proposta e as ações desenvolvidas pela Incubadora de Tecnologias Sociais e Solidárias da UFGD (ITESS).

As reflexões teóricas que serviram de base para o fomento das reflexões que se desdobraram na pesquisa, se deram no sentido de identificar potencialidades de valorização de práticas sociais, invisibilizadas por modelos de conhecimento e de produção científicas hegemônicas, conforme teorizado por Boaventura de Souza Santos (2007).

Para a realização da metodologia de pesquisa, o grupo de pesquisadores responsáveis esteve munido de caderno de campo, gravadores de voz, câmera fotográfica e de filmagem. O procedimento padrão adotado foi o de agendamento prévio das conversas/entrevistas, trabalho este intermediado pelos parceiros da Universidade Eduardo Mondlane (UEM), sobretudo do Centro de Análise de Políticas (CAP). Quando o agendamento prévio não era realizado, as interlocuções eram realizadas pelo próprio grupo de pesquisadores brasileiros. É possível afirmar que quando do uso de interlocuções diretas houve maiores dificuldades no alcance dos objetivos de campo.

De modo geral, é possível afirmar que a(s) realidade(s) com a qual estabeleceu maior proximidade possui uma lógica intrínseca de saberes edificados sobre os territórios em questão. Territórios estes constituídos por processos inclusivos por si só, uma vez que são produzidos pela cooperação sujeitos-sujeitos e sujeitos-natureza, como bem assevera Porto-Gonçalves (2012).

O valor incomensurável que estes territórios possuem decorre do fato de eles ainda não terem sido intensamente desarticulados pelo processo da modernização capitalista e que, apesar dos problemas, em termos dos ditos "índices de desenvolvimento", da baixa industrialização - baixo consumo de industrializados no mercado interno, número reduzido de pessoas inseridas no mercado de trabalho formal, dentre outros -, 
essa realidade significa, por outro lado, a manutenção de modos de vida rural/agrário, que caso desarticulados tendem a produzir os problemas já verificados em grande parte do modo de vida das populações de países do mundo industrial desenvolvido e subdesenvolvido ${ }^{1}$.

Sendo assim, decorrente desta distinção espaço-temporal, torna-se possível assegurar e potencializar certas características das práticas territoriais destes grupos, por excelência solidárias, na medida em que estes passem a ser submetidos ao avanço das relações capitalistas e do processo de globalização.

\section{Breves aspectos histórico-geográficos do lugar de pesquisa: As singularidades do espaço urbano de Maputo/MOZ}

Antes de iniciar o destaque à centralidade das práticas sociais e saberes de mulheres e homens e a produção do território rural em Moçambique, é preciso fazer algumas considerações gerais sobre o que se apreendeu do espaço geográfico moçambicano e, de modo mais específico, acerca das singularidades presentes no recorte espacial desta experiência de pesquisa: a capital Maputo e seu entorno próximo. Tais apontamentos, serão endereçados aos significados do rural e do urbano e, na medida do possível, da confluência de ambos.

No que diz respeito à propriedade da terra, toda a cidade de Maputo - local onde nos alocamos durante a realização da pesquisa, seu entorno rural, e demais localidades do país possuem o acesso à terra regulado por dois tipos de uso: a) o Uso consuetudinário; e b) Uso e aproveitamento do solo / Uso tradicional da terra, que estão incorporados como dispositivo legal na Lei Nacional de Terras (1997).

Em 1975, após a conquista da independência em relação a Portugal, sob o comando da FRELIMO (Frente pela Libertação de Moçambique), o uso coletivo da natureza/terra foi incorporado legalmente à constituição da República Popular de Moçambique. Algo que, sob a tradição institucional das sociedades ocidentais, assume o caráter de nacionalização/estatização da terra.

\footnotetext{
1 Problemas de saúde decorrente do consumo exagerado de industrializados; intensificação da poluição das águas superficiais, por dejetos industriais e do esgotamento urbano; alimentação de baixo valor nutricional agregado; dependência alimentar dos grandes oligopólios agroindustriais, dentre outros, facilmente verificados nas sociedades urbano-industriais.
} 
Figura 1. Machamba situada lado a lado à uma importante avenida de Maputo. Autora: Delboni, 2015.

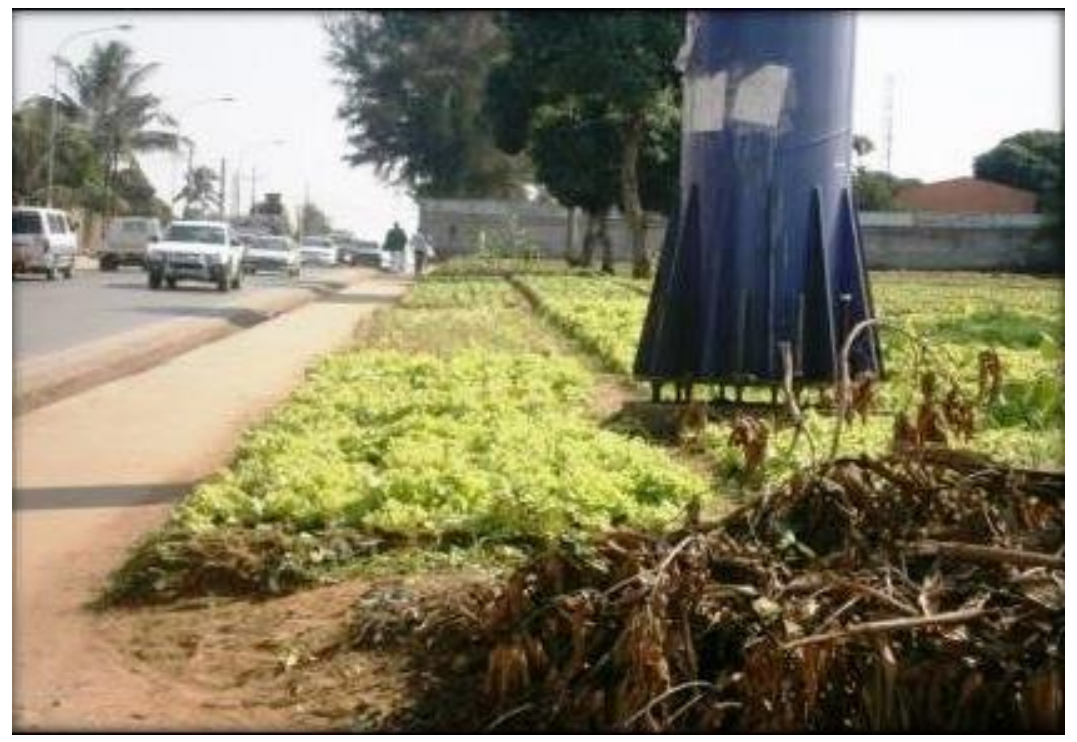

Trata-se de um "caminho contrário" do adotado no Brasil, por exemplo, onde o uso corriqueiro da terra, enquanto garantidor de sua posse, paulatinamente foi eliminado, para afirmar e assegurar a propriedade privada da terra, aprovada no ano de 1850, no contexto de pós-independência.

Na prática, isso se expressa numa forte presença, até então, do uso em relação à troca. No entanto, isto tem se transformado ao passo que a relação de troca se expande. Seria, por exemplo, como se ao invés de utilizar determinada área de terra para cultivar um jardim, com flores, plantas ornamentais, característica de uma relação estética/artificializada com a Natureza no urbano, prevalecesse a Machamba (Figura 2) ${ }^{2}$, resultado, possivelmente, de uma relação mais orgânica entre homem e natureza, além, é claro da trajetória histórica do país com relação ao processo de urbanização, com características singulares ${ }^{3}$.

Em termos de desdobramentos espaciais deste fenômeno social, tem-se uma morfologia urbana muito específica. Abaixo, na Figura 2, por exemplo, temos uma visão aérea de Matola, capital da província de Maputo, situada no subúrbio da cidade de Maputo, capital do país, com a qual se encontra conturbada:

\footnotetext{
${ }^{2}$ S. f. [Moçambique] terreno agrícola para produção familiar; terreno de cultivo. Do changana maxamba, «idem». Fonte: <http://www.dicionarioinformal.com.br/machamba/> Acesso em: 05/08/2015.

${ }^{3}$ No caso da singularidade do processo de urbanização em Moçambique, e em África de uma forma mais geral, a urbanização não ocorreu associada, necessariamente, à uma intensificação da atividade industrial e do aumento dos núcleos urbanos em quantidade e amplitude, decorrente diretamente desse processo. É a Guerra que forçou com que as pessoas migrassem para a cidade sem, no entanto, estabelecer o rearranjo voltado à indústria, sob um conteúdo tipicamente urbano, ligado à produção/consumo.
} 
Figura 2. Vista aérea da cidade de Matola (2004), situada no subúrbio de Maputo. Fonte: Google Earth.

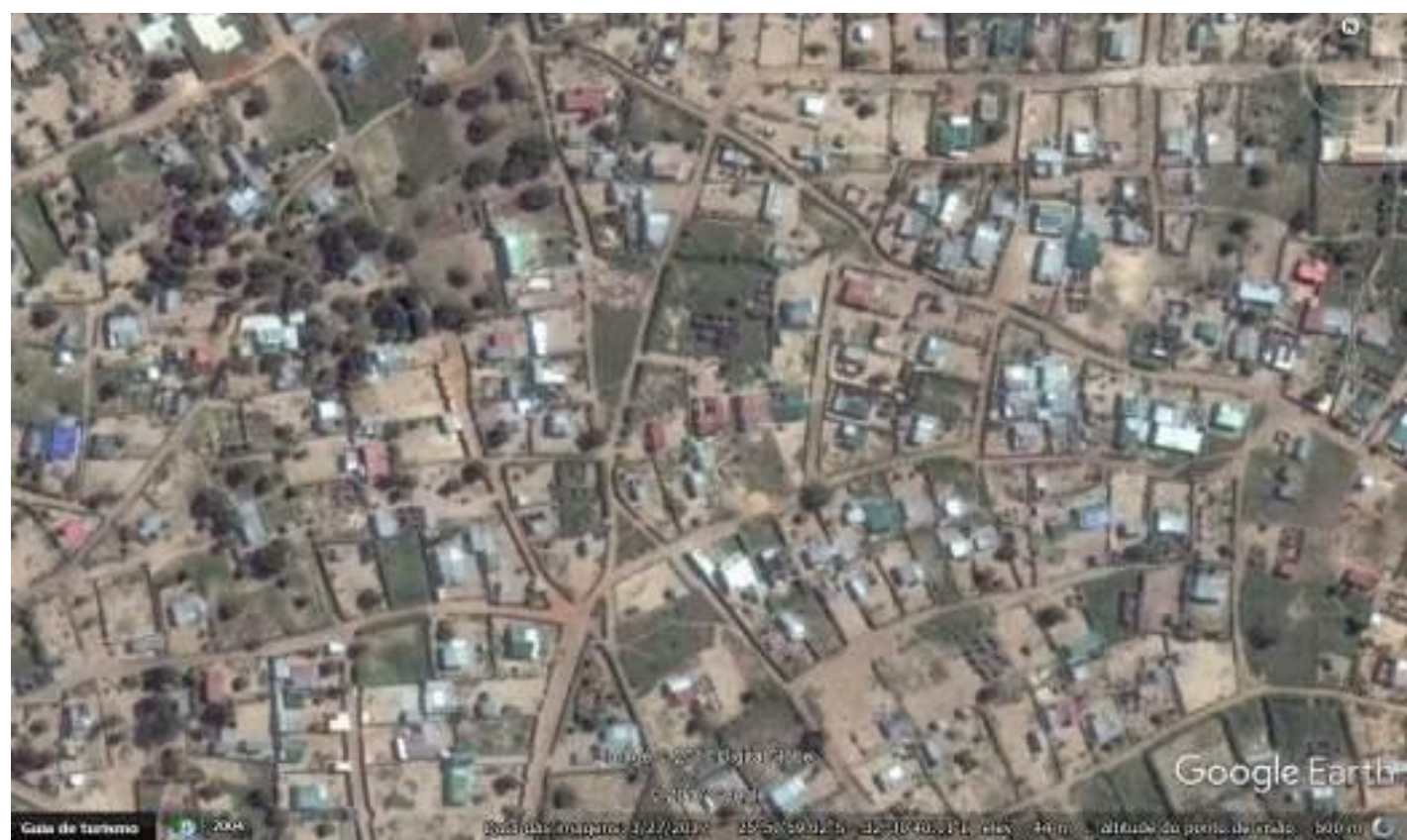

Apesar de sua importância industrial (Figura 3), concentrando um conjunto de indústrias de base e de bens de consumo, esta, cumpre a função também de cidade dormitório, onde os moradores/trabalhadores realizam movimento pendular diário para Maputo (cidade maior, com atividade industrial e sobretudo comercial).

Figura 3. Aglomerado de indústrias no distrito de Boane, muito próximo à Matola. Autor: Campos, 2015.

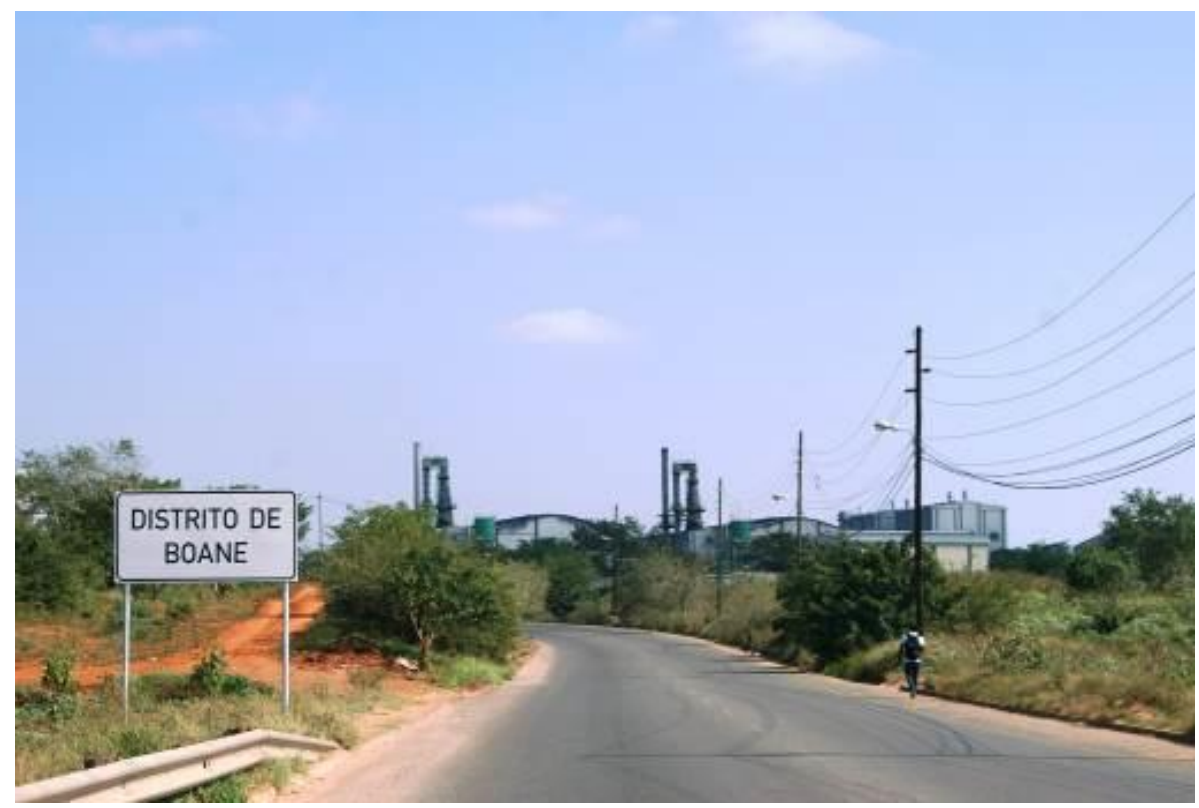


Outra parcela da população desempenha atividades tipicamente agrícolas, ligadas ao cultivo da terra para produção de alimentos ${ }^{4}$, mesmo que situadas geograficamente num espaço como a cidade ${ }^{5}$. Deste modo, é preciso considerar que estamos tratando de um espaço urbano - que possui funções e papéis históricogeograficamente específicos ${ }^{6}-$-, e indagar-se sobre como se constituiu o urbano em Moçambique ${ }^{7}$.

Figura 4: Estrada que liga a cidade de Maputo à zona de cinturão verde Infulene. Autora: Delboni, 2015.

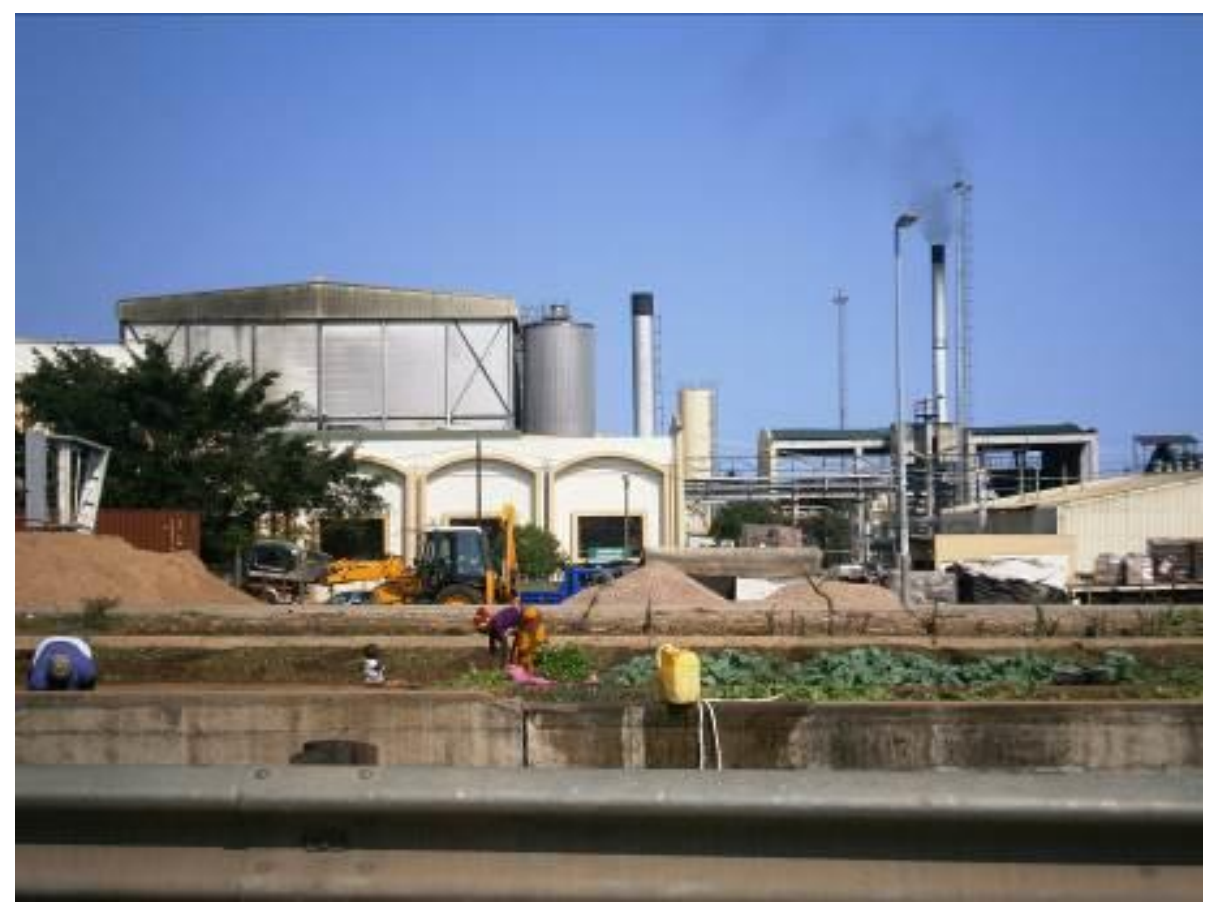

${ }_{4}^{4}$ Apesar do rápido processo de urbanização, em 2009 ainda só 39\% da população da Matola vivia na zona urbana, 14\% na zona rural e os restantes $47 \%$ na zona peri-urbana ou suburbana.

${ }^{5}$ Refletindo sobre este aspecto, provavelmente ao observar atentamente alguma cidade brasileira, o geógrafo Marcelo Lopes de Souza aponta que "A cidade é, sob o ângulo do uso do solo, ou das atividades econômicas que a caracterizam, um espaço de produção não-agrícola (ou seja, manufatureira ou propriamente industrial) e de comércio e oferecimento de serviços. (...) Ocorre, porém, que a coisa não é tão simples assim. Não é tão simples, não tanto porque, às vezes, podem ser encontradas, como minúsculas ilhotas em meio a um oceano de espaço construído, 'extravagâncias especiais', como plantações de hortaliças, verduras e legumes (olericultura), desenvolvidas debaixo de torres de alta tensão - ou seja, em terrenos que, dificilmente se prestariam para qualquer outros aproveitamento econômico" (SOUZA, 2013, p. 27).

6 "Toda cidade é, do ponto de vista geoeconômico, isto é, das atividades econômicas vistas a partir de uma perspectiva espacial, uma localidade central, de nível maior ou menor de acordo com a sua centralidade - ou seja, de acordo com a quantidade de bens e serviços que ela oferta, e que fazem com que ela atraia compradores apenas das redondezas, de uma região inteira ou, mesmo, de acordo com o nível de sofisticação do bem e do serviço, do país inteiro e até de outros países. A aldeia (ou, para adaptar à realidade brasileira, o povoado, já que aldeia é um termo que, entre nós, remete, em primeiro lugar, a assentamentos indígenas), diversamente, não é uma localidade central. A natureza da aldeia, ou do povoado, é mais "centrífuga", para usar um termo de Christaller, porque as atenções de seus moradores estão voltadas para as suas bordas (onde começam os campos de cultivo), do que "centrípeta", como ocorre com a cidade, onde a área central de negócios (em inglês, central business district, ou CBD), ou o seu embrião, atrai os consumidores de todo tecido urbano, fazendo com que as atenções dos citadinos se voltem para o centro do assentamento e não para suas franjas" (SOUZA, 2013, p. 25-26).

7 "Antes de 1850, informa-nos Kingsley Davis, nenhuma sociedade poderia ser considerada como predominantemente urbana, e por volta de 1900 só a Grã-Bretanha o era. Hoje, um século depois, somente no grupo dos países de mais baixo nível de desenvolvimento econômico (principalmente na África do Sul do Sahara e na Ásia das monções) é que ainda preponderam os países cuja população é predominantemente rural" (SOUZA, 2013, p. 20). 
Manuel Araújo (1988) defende que, para o estudo de Moçambique, deve-se adotar uma classificação de urbano com base nos seguintes critérios:

- Organização administrativa, segundo o qual será urbana toda a população que vive nas capitais provinciais;

- Número de habitantes, considerando-se urbanos os aglomerados com 10.000 e mais residentes;

- Existência de infraestruturas socioeconômicas, como sejam: serviços (saúde, ensino, administração, água, luz, et.), comércio, construção, transportes e comunicações;

- Função económica, que deve situar-se maioritariamente fora do setor agrário;

- Papel histórico desempenhado pelo centro populacional e perspectivas de desenvolvimento dos setores secundário e terciário. (MANUEL ARAÚJO, 1988, p. 21-22). (grifos do autor).

Isso se justifica, uma vez que em Maputo, capital nacional, observa-se que a paisagem urbana coexiste lado a lado com o ambiente rural, uma vez que o primeiro não se afirma de forma suficientemente coesa sobre o segundo.

\footnotetext{
O fenómeno urbano em África não é o resultado, como sucedeu na Europa e América do Norte, duma revolução industrial; no nosso continente ele assume características exclusivamente demográficas. Isto significa que o crescimento das cidades se faz apenas com a aglomeração de população de origem rural, tendo pouco significado, ou mesmo nenhum, o desenvolvimento industrial. (ARAÚJO, 1997, p. 18).
}

Neste caso, observamos a permanência do tradicional uso do solo para o cultivo agrícola (Figura 5), no qual ainda as características físicas de fertilidade do solo interferem em seu valor, sendo o espaço não apenas mediado pelo valor de sua localização como suporte para atividades tipicamente urbanas. Isto ocorre como decorrência da insuficiência de outras condições objetivas-materiais, ou seja, os meios para o estabelecimento da dinâmica urbano-industrial. Persiste, assim, a presença dos meios técnicos orientados a garantir as condições objetivas típicas do modo de vida rural.

\section{O distrito de Marracuene e o comércio das mulheres na feira}

No Distrito de Marracuene, presenciamos a dinâmica de uma feira onde as mulheres estendiam suas esteiras, plástico, kapulana e sobre elas dispunham uma diversidade de produtos - cacana, tseque, tiaqua, couve, folha de abobora, repolho, alface, tomate, pepino, mandioca, tangerina, banana, batata, cebola, sal grosso, batata doce, amendoim, feijão, limão, coco, pilão, kapulanas, etc. 
Figura 5. Localização de Marracuene em relação aos conjuntos de Machambas de seu entorno. Fonte: Google Earth. Edição: Campos, 2018.

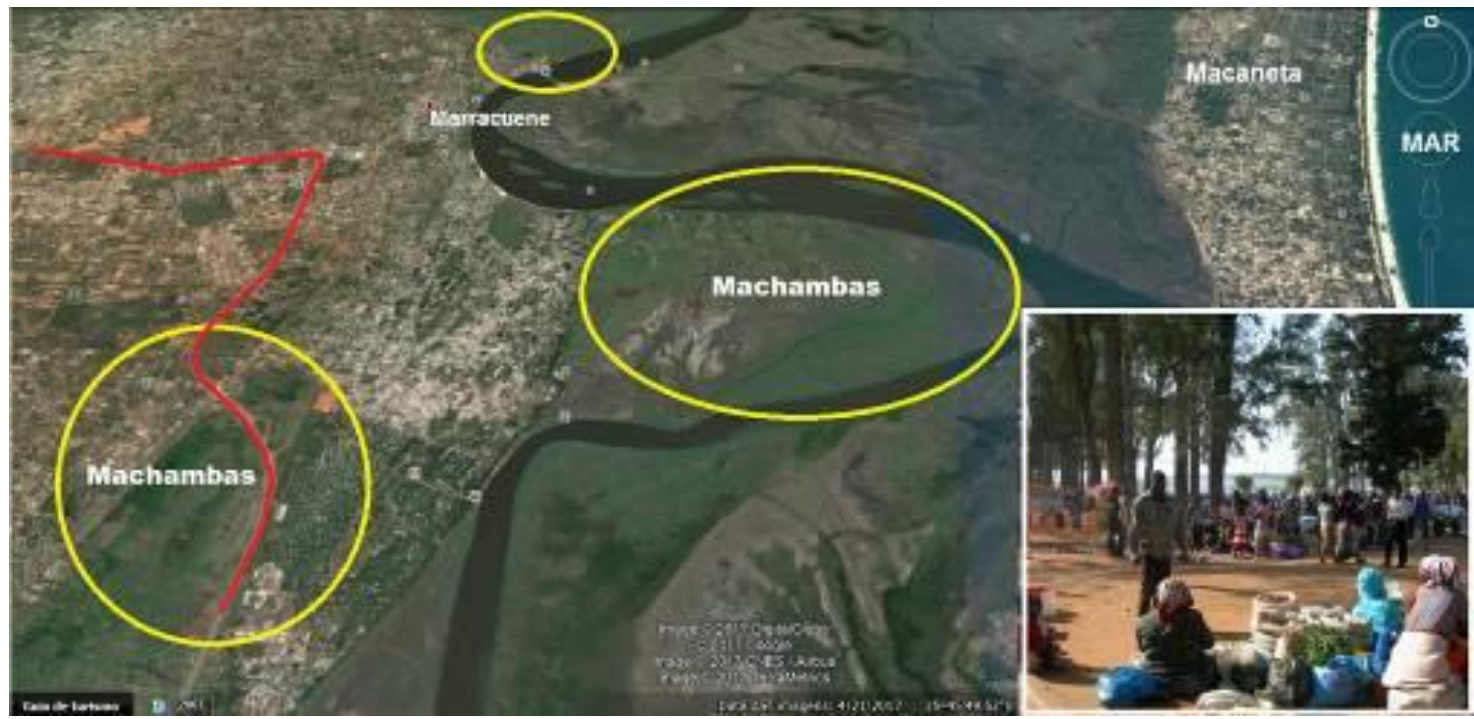

Figura 6: Vista geral da dinâmica de pessoas e mercadoria na Feira de Marracuene. Autora: Delboni, 2015.

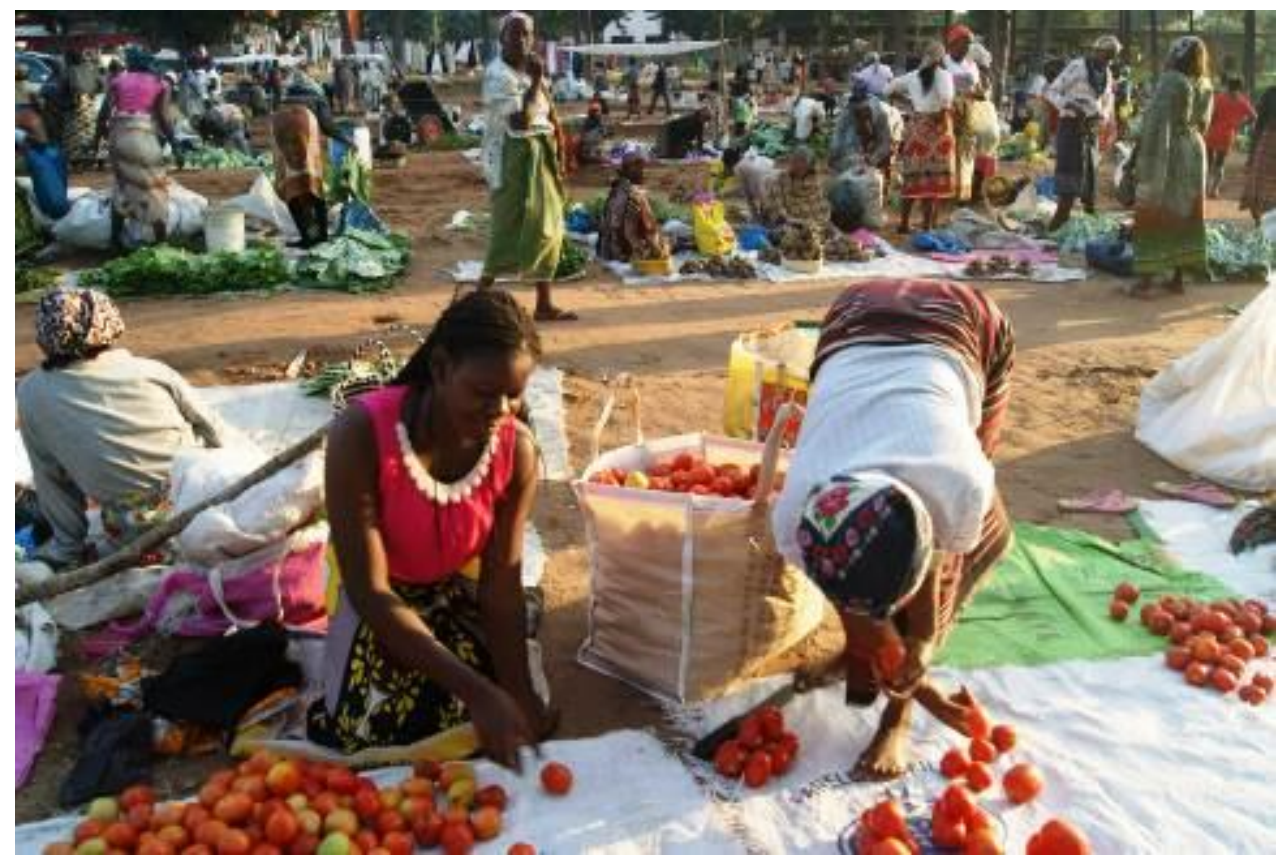

Atendo-se para os dados referentes à escolarização, por exemplo, requisito básico para inclusão socioeconômica nas sociedades moderna-industriais, tem-se a devida dimensão do papel que o cultivo de itens agrícolas desempenha na viabilização da vida destas pessoas. 
A educação é baixa (as matrículas para o ensino primário ultrapassam $80 \%$, mas somente um terço completa a educação primária). Os índices de analfabetismos são altos e atingem $38.7 \%$, principalmente nas zonas rurais entre mulheres (UNAC, 2010, p. 10).

Recorrendo o Censo Agropecuário de 2010, Uaiene (2012, p. 51) indica que "cerca de 63\% das mulheres chefes de agregados familiares (AF) não sabem ler nem escrever enquanto apenas cerca de $32 \%$ dos homens que chefiam os AF caem na mesma categoria".

A tabela 1 faz referência às diferenças em termos de níveis de escolaridades entre AF chefiados por mulheres e AF chefiados por homens embora precise também de uma atualização, mas revela um pouco daquilo que se tem registado no meio rural moçambicano.

Tabela 1: Níveis de escolaridades dos chefes dos agregados familiares (\%). Fonte: Organizada pelo autor a partir de Uaeine (2012).

\begin{tabular}{cccc}
\hline Escolaridade & Homens & Mulheres & Total \\
\hline Não sabe ler nem escrever & 31.7 & 62.9 & 40.3 \\
Alfabetização & 13.8 & 14.8 & 14.1 \\
Primeiro grau & 26.9 & 12.7 & 23.0 \\
\hline
\end{tabular}

Logo que chegamos, começamos a conversar com as mulheres e percebemos a dificuldade de aproximação principalmente com as mulheres mais velhas. A estratégia foi comprar os produtos, enquanto pesquisávamos os diversos trabalhos realizados por elas na dinâmica da feira. Contudo, outro empecilho foi não encontrarmos moedas para realizarmos o trâmite comercial: era um comércio de centavos, realizado por moedas.

A língua também representou uma dificuldade na comunicação, pois muitas mulheres mostravam um português carregado pela língua local e dificuldade para compreenderem os questionamentos da pesquisa. Também se mostraram resistentes às fotografias, principalmente as mais velhas. Inclusive, uma delas confidenciou que se estivesse em casa permitiria, afinal estava numa situação de trabalho, sem nenhum cuidado estético; outra permitiu fotografar em troca dos cinco meticais, que era o troco da compra.

Realizamos entrevista com três mulheres, Monica, Persina e Benvinda. Foram conversas curtas, uma vez que a cada pergunta lançada sobre suas vidas, pareciam assustadas, ainda mais quando adentrava sobre suas vidas privadas, como o estado civil, a quantidade de filhos e idade. A possibilidade de gravar as conversas foi logo descartada, assim a cada entrevista realizada recorremos às anotações no caderno de campo, para que as informações não se perdessem. 
Monica nasceu em Marracuene, tinha 37 anos e não estudou. Plantava os produtos que produzia na Machamba, mandioca e batata doce que comercializava nas terças e sábados. Perguntamos se poderia tirar uma foto e ela concordou. Persina havia estudado até a 11a classe. Nasceu em Marracuene e tinha sua machamba onde produzia mandioca, batata e pepino. Ela permitiu que tirássemos uma foto, mas não respondeu os questionamentos sobre estado civil e número de filhos que possuía.

Figura 7. Vista geral da dinâmica de pessoas e mercadoria na Feira de Marracuene. Autora: Delboni, 2015.

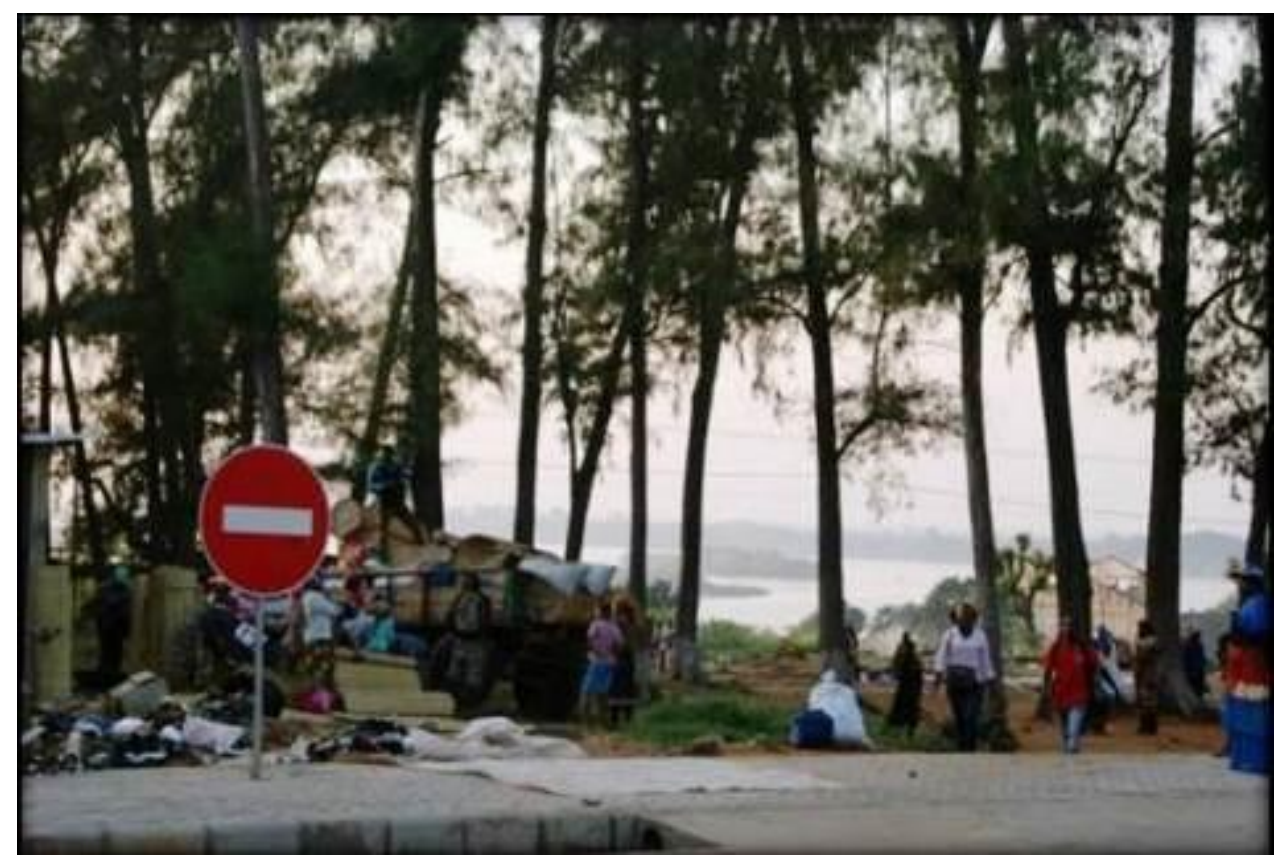

Os dados da tabela 2 demonstram que a população empregada na agricultura no campo não variou tanto nos últimos anos, apesar do crescimento da população urbana.

Tabela 2. Emprego por setor de atividade ao longo do tempo (\%). Fonte: Catsossa, Lucas (2017).

\begin{tabular}{lllll}
\hline Setores de atividades & $\mathbf{1 9 9 0 - 9 5}$ & $\mathbf{1 9 9 6 - 2 0 0 0}$ & $\mathbf{2 0 0 1 - 0 5}$ & $\mathbf{2 0 0 6 - 0 7}$ \\
\hline Agricultura & 81.5 & 80.9 & $\mathbf{7 9 . 9}$ & 76.1 \\
Recursos naturais & 0.9 & 0.6 & 0.5 & 0.6 \\
Manufatura & 3.8 & 3.4 & 3.2 & 3.2 \\
Energia & 0.1 & 0.1 & 0.2 & 0.2 \\
Construção & 1.4 & 2.0 & 2.2 & 2.5 \\
Comércio & 4.2 & 6.5 & 7.7 & 7.6 \\
Transporte, comunicação e armazenamento & 1.2 & 0.5 & 0.9 & 1.1 \\
Outros & 6.8 & 6.1 & 5.5 & 7.4 \\
\hline
\end{tabular}


No que tange as especificidades do modo de vida das pessoas com as quais se estabeleceu contato, no sentido de melhor conhecer as estratégias de permanência na terra, de geração de trabalho e renda, percebemos que o entorno de Maputo, seja o Distrito de Marracuene (Figura 8), ou outras áreas rurais, é marcado por um rural que, como já dito, demanda outros referenciais para sua compreensão. O urbano e o rural se confundem a todo instante.

Figura 8. Paisagem na cidade de município de Xai-Xai, ao norte de Maputo. Autor: Moretti, 2015.

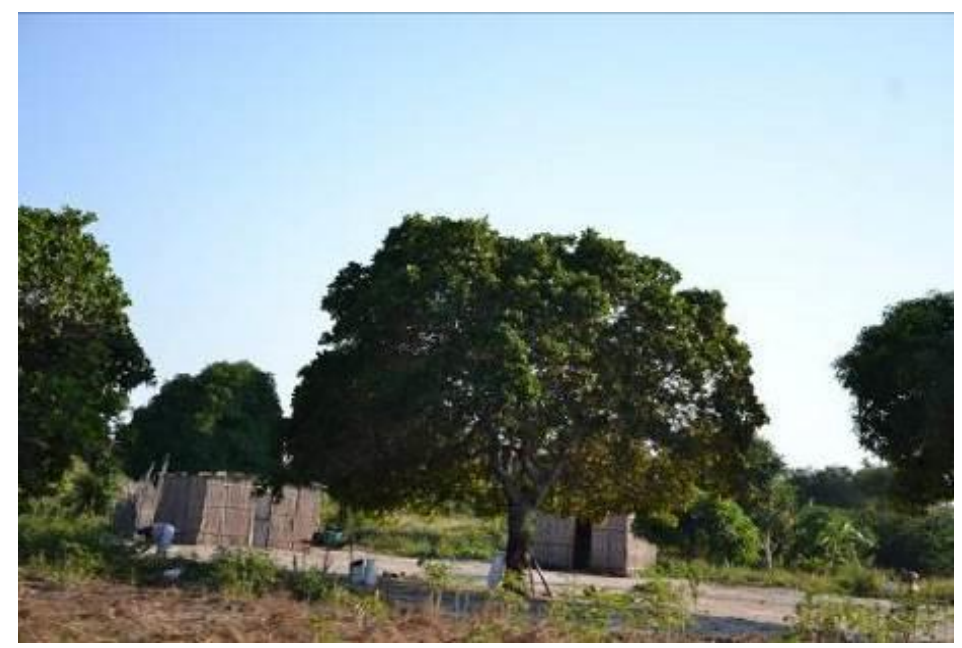

Outro exemplo, que podemos mencionar, nesta mesma perspectiva verificada no Distrito de Marracuene, é a região do entorno de Xai-Xai. Neste local, onde se cumpriu parte da pesquisa, verificamos, na área urbana, uma ocupação dispersa, com pouco adensamento de infraestruturas e a presença de muitas práticas rurais. As famílias parecem se agrupar em torno das parentelas, em ocupações que não possuem delimitação padronizada dos loteamentos e divisão dos lotes, e isto tende a se "urbanizar" com pouca alteração do ambiente físico.

São "manchas de ocupação" pouco adensadas ${ }^{8}$ (Figura 8), que se estendem por quilômetros, numa cidade que possui menos de 150.000 habitantes. Com árvores, vegetação nativa ainda existente, um híbrido inimaginável para a nossa realidade, urbanização talvez seja um conceito equivocado para descrever tal realidade. Como falar, por exemplo, em arborização urbana, se muito pouco foi desmatado? O que ali está

\footnotetext{
8 "Os organismos internacionais especializados das Nações Unidas, embora deixando aos países a decisão da definição de rural e urbano, recomendam para a África um número de $\mathbf{1 0 . 0 0 0}$ a $\mathbf{2 0 . 0 0 0}$ habitantes, como aquele a partir do qual se deve considerar o povoamento como urbano, pois a aglomeração deste número de pessoas num espaço relativamente reduzido implica a necessidade da existência de infraestruturas urbanas básicas" (ARAÚJO, 1998, p. 20-21). (Grifo nosso).
} 
desarborizado para ter que rearborizar? Trata-se de outra lógica de produção, apropriação e consumo do espaço, que não deve ser questionada e sim melhor compreendida.

Percebemos, neste lugar, a vastidão de um campo marcado pela presença da agricultura de subsistência. Uma agricultura caracterizada pela ausência de tecnologia rebuscada, feita na enxada, mas que parecia possibilitar o necessário para a garantia da reprodução familiar.

Figura 9. Mulher caminha transportando uma espécie de fibra típica sobre a cabeça. Autor: Moretti, 2015

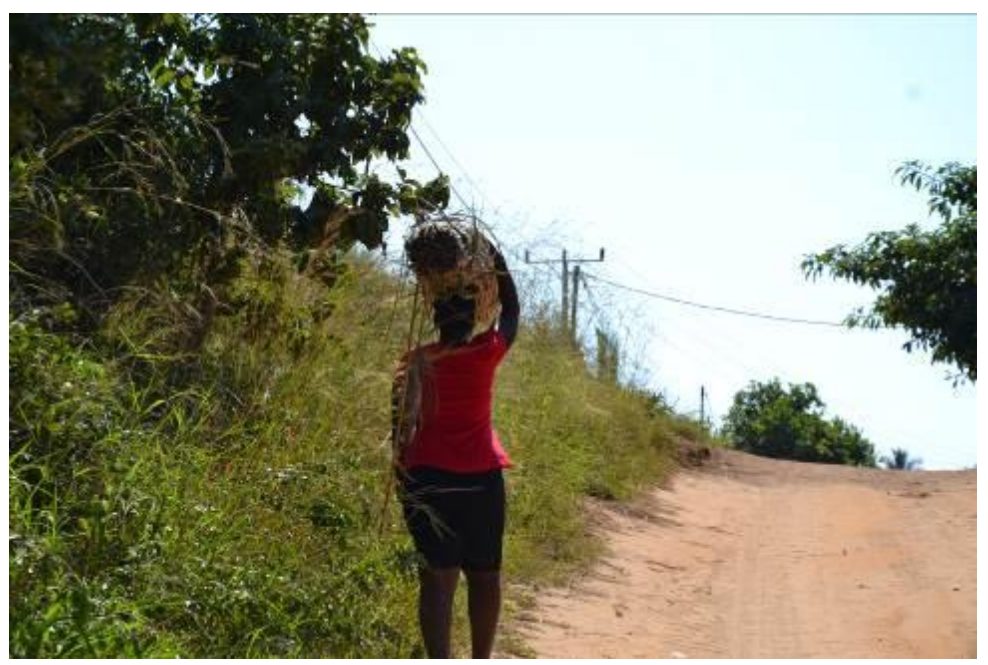

Na estrada, havia muitos transeuntes na beira do asfalto. Havia, também, muitas mulheres carregando mercadorias na cabeça (Figura 9), além de comerciantes de frutas, castanhas e até coelhos.

\section{As machambas e as mulheres na produção da economia doméstica}

Ainda acerca da produção desse espaço de feição agrícola/agrária, teve-se contato com o Vale do Infulene. Considerado o cinturão verde da Cidade de Maputo, este concentra um grande percentual de famílias produzindo alimentos, principalmente hortaliças e legumes. Ao longo do Vale do Infulene há uma área estatal ${ }^{9}$ destinada, especificadamente, para este tipo de cultivo.

\footnotetext{
9 "Toda terra pertence ao Estado, mas procura proteger os direitos de terra dos camponeses, através do reconhecimento dos direitos de ocupação da terra e reconhece formalmente as normas e práticas costumeiras como canais legítimos através dos quais se pode adquirir terra" (WATHERHOUSE e VIJFHUIZEN, 2001).
} 
Figura 10. Pessoas cuidam de Machamba no Vale do Infulene, cinturão verde de Maputo. Autor: Campos, 2015.

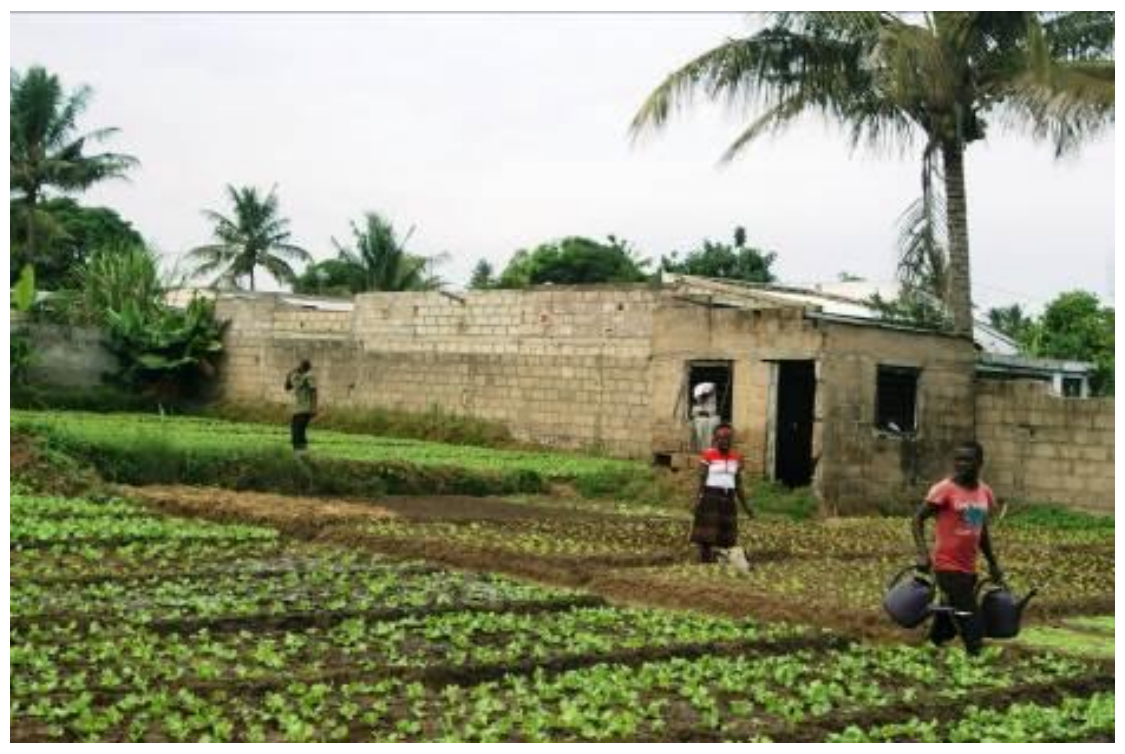

No caminho, até chegar nesta área, há uma produção agrícola urbana, que ocupa as frentes e os quintais das casas (Figura 10). São principalmente mulheres, acompanhadas de suas filhas e filhos, que, organizadas numa cooperativa, sob o controle e tutela do Estado, trabalham diariamente neste conjunto coletivo de Machambas $^{10}$.

Figura 11. Machambas em frente às casas no Vale do Infulene, Maputo. Autor: Campos, 2015.

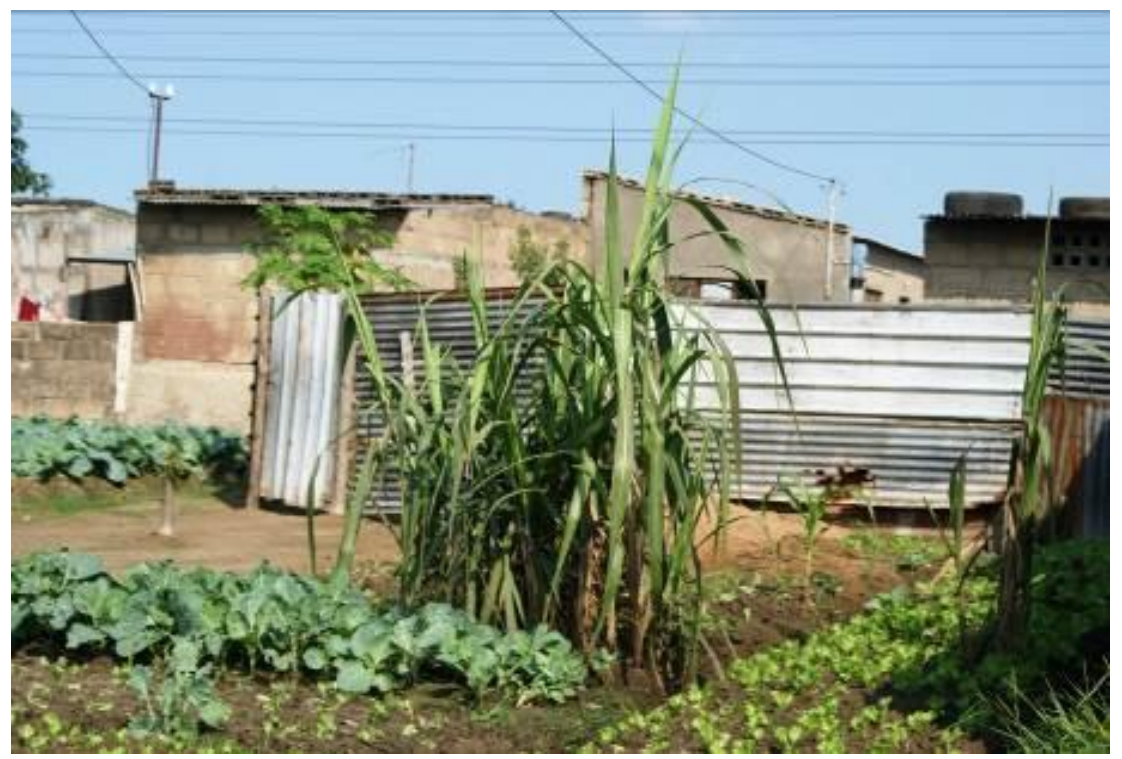

$10 \mathrm{~S}$. f. [Moçambique] terreno agrícola para produção familiar; terreno de cultivo; Do changana maxamba, «idem». Fonte: <http://www.dicionarioinformal.com.br/machamba/> Acesso em: 05/08/2015. 
Nas machambas de Infulene realizamos uma entrevista com Nádia, nascida em Xai Xai e agricultora no cinturão verde. Trabalhava junto com a tia na produção de mudas de cebola, beterraba, alface, couve e outras hortaliças. Logo de imediato nos contou sobre seu sonho de vir para o Brasil, muito alimentado por meio das novelas: um dia ela haveria de conhecer sua beleza!

Ela morava nas franjas da capital de Maputo (Matola), cidade marcada pela parca presença de indústrias e pelos altos índices de desemprego. Na machamba Nádia tinha uma casa, um trabalho, a proximidade dos parentes. Naquele lugar, os habitantes migrantes de diversas regiões de Moçambique produziam o sustento das suas existências e também o de muitos consumidores e agricultores da cidade que compravam mudas para fazerem suas hortas nos jardins das suas casas (ex: Figura 10).

Confidenciou em entrevista conduzida pela equipe de pesquisa que era feliz naquele espaço, pois se sentia responsável pela produção da vida. Estava perto de seus parentes - a tia com seus dez primos, não precisava comer frutas e verduras velhas comercializadas pelo asfalto da capital, sob alta temperatura na exposição ao sol.

Figura 12. Paisagem da cidade de Maputo. Autora: Delboni, 2015.

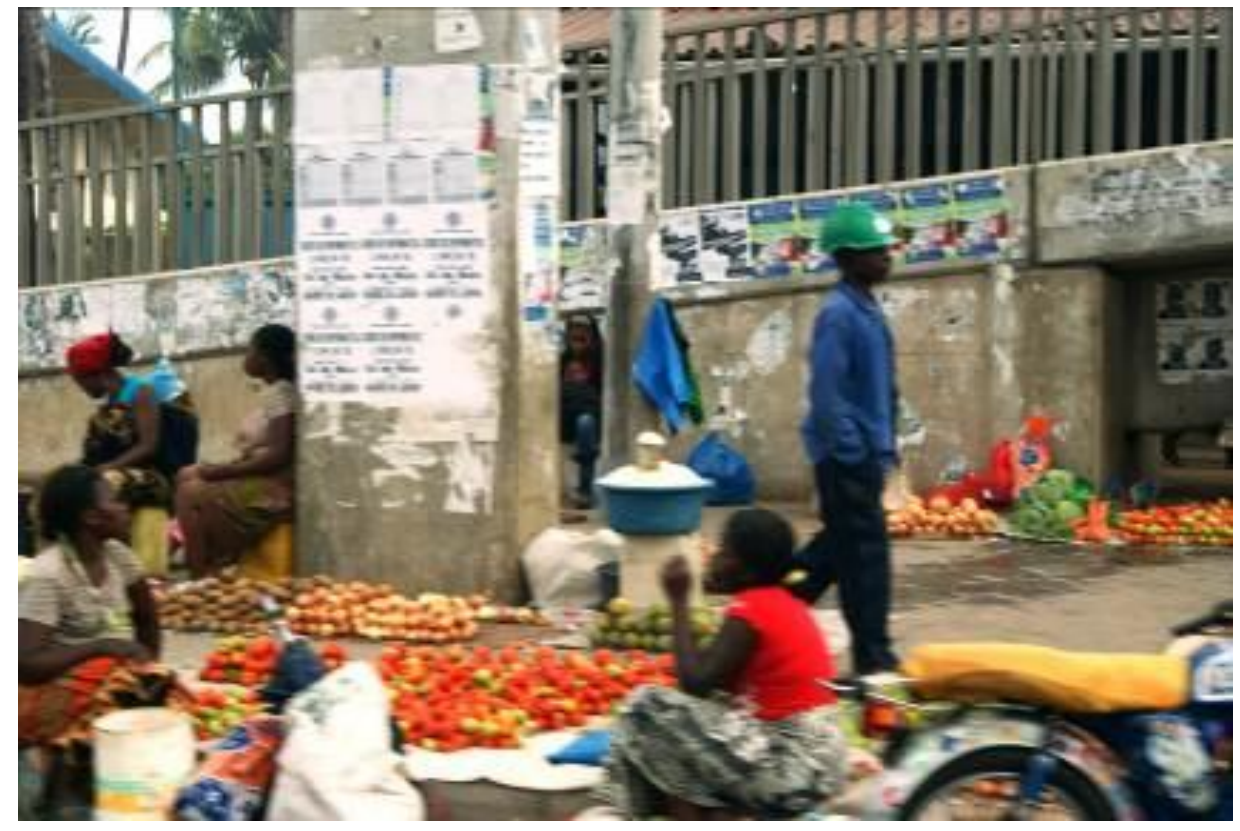

Ela tinha os meios de produção e reprodução da vida! Nas machambas encontramos menor resistência à fotografia. 
Figura 13. Vista geral Machamba localizada no cinturão verde de Maputo. Autora: Delboni, 2015.

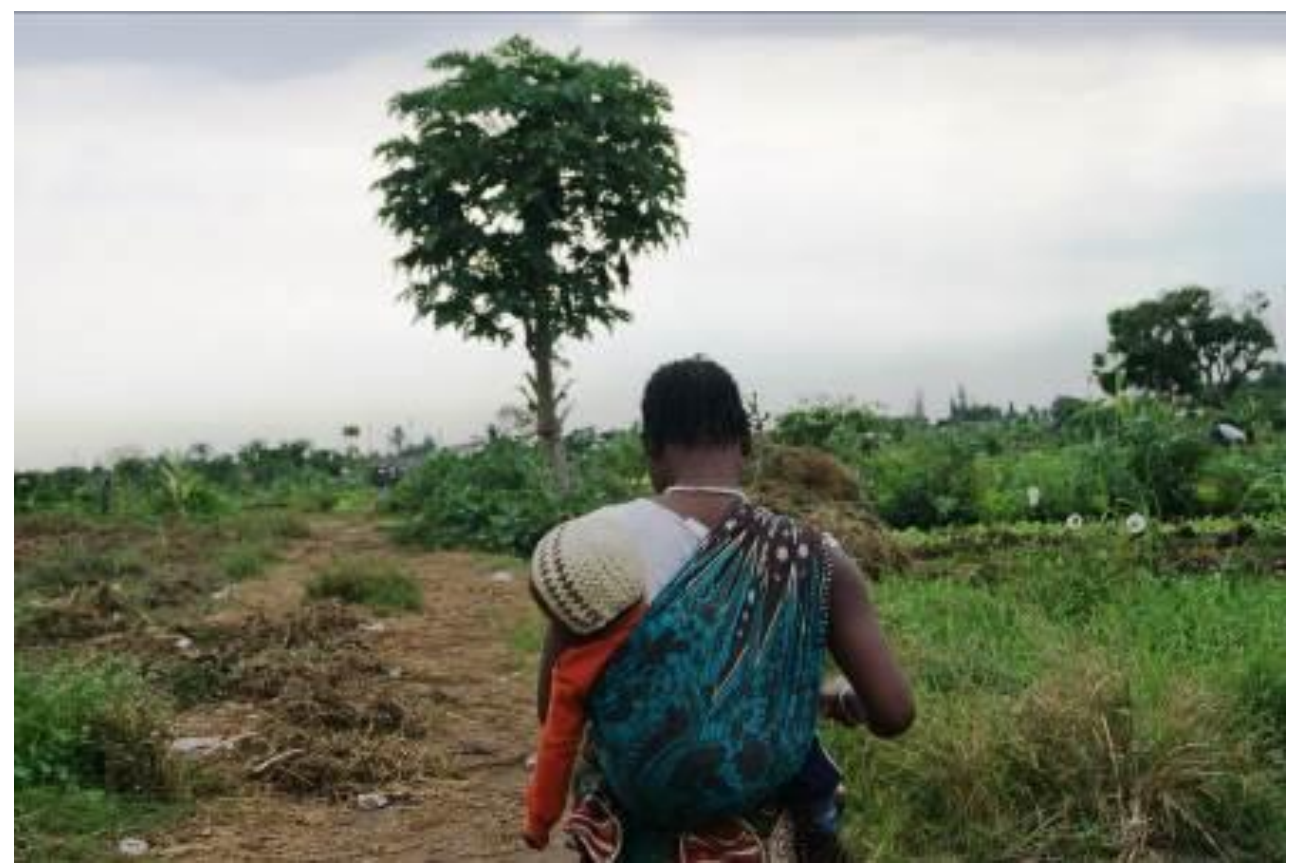

Algumas mostraram felizes e pousavam sob a lente da câmara fotográfica, pareciam orgulhosas de sua condição de produtoras de alimentos e provedoras da economia doméstica que proporcionava a produção da extensa família, como Nádia que dividia a moradia com mais dez primos, sob companhia da tia.

\section{Chindeguele: potencialidades e limites da atividade turística}

Nesta mesma perspectiva, das peculiaridades de apropriação e uso do espaço, podemos afirmar, de início, que o território turístico da praia de Chidenguele, na região de Xai-Xai, é constituído de uma paisagem pouco alterada, estando, predominantemente, ocupado e utilizado por práticas locais tradicionais, apesar da já intensa presença do segmento turístico de feição capitalista. Diríamos que, apesar disto, há ainda forte presença de elementos da natureza com pouca artificialização e também do uso tradicional dos mesmos. A relativa baixa intensidade da entrada de capitais, ou seja, pouca apropriação capitalista do espaço, permite que este local mantenha suas belezas naturais sensivelmente preservadas.

Trata-se de uma paisagem muito diferente dos locais onde o grande capital se apropria e produz artificialmente o espaço turístico. Com paisagem rústica, pouco alterada, Chidenguele ainda é uma possibilidade aberta para a promoção e o fortalecimento do turismo de base comunitária, principalmente quando consideramos o uso tradicional que ainda se realiza (d)neste espaço. Ou seja, a apropriação e 
organização coletiva ainda não foram destruídas, podendo ser fortalecidas para o uso do território turístico de base comunitária. No entanto, apesar de o turismo ser uma possibilidade evidente, é preciso que a esfera pública e privada oferte uma infraestrutura mínima precedente para sua realização.

Neste mesmo sentido, de melhor compreender a organização do circuito turístico no país, foi realizada entrevista com o presidente do Sindicato dos Trabalhadores na Indústria do Turismo. Segundo o presidente, o sindicato conta com 53.710 trabalhadores filiados, sendo que destes, 29.150 são homens e 24.560 são mulheres. São trabalhadores do circuito turístico de Moçambique, sendo constituído, sobretudo, por funcionários de hotéis e resort. No sindicato são 31.730 sócios e destes 12.440 são mulheres e constatamos que não há mulheres na direção do sindicato.

Figura 14. Território turístico de Chidenguele, na região de Xai-Xai. Autor: Campos, 2015.

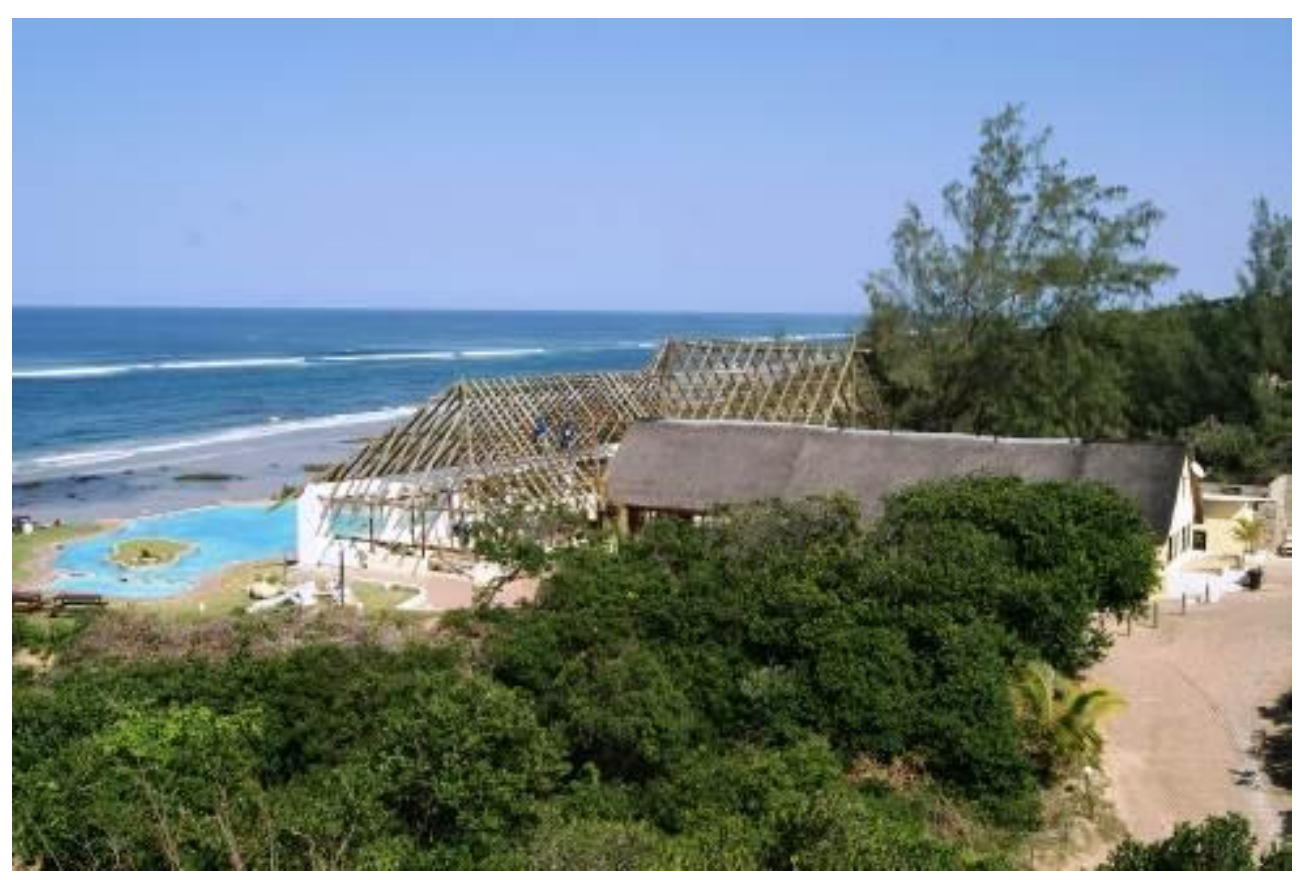

De acordo com o presidente do sindicato o salário base da categoria é de 4.676 Meticais (moeda local ${ }^{11}$ ). O salário médio, no entanto, gira em torno de 8.000 Meticais. Atualmente, as principais lutas da categoria estão pautadas na reivindicação de 90 dias de afastamento para gestantes, 13오 salário, abono de férias e previdência social.

\footnotetext{
${ }^{11}$ Atualmente, R\$1,00 equivale a Mt. 16.48 (Fonte: https://pt.coinmill.com/BRL_MZN.htmI\#BRL=1 . Acesso em: 15/05/2018).
} 
Sobre os principais investidores do segmento no país, foi informado que os capitais são provenientes, principalmente, do mercado estrangeiro (África do Sul e Itália principalmente). Isto preocupa quando consideramos que nas relações sociais e de produção no país é notório o moçambicano negro, maioria absoluta da população, sendo subjugado em seu próprio país por brancos (portugueses e sul-africanos), Indianos e Árabes.

\section{CONSIDERAÇÕES FINAIS}

É possível destacar, de imediato, como consideração a se realizar, as singularidades presentes no recorte espacial desta experiência de pesquisa: a capital Maputo e seu entorno próximo. Trata-se de algo intensamente impactante para pessoas que habitam os países industrializados do mundo desenvolvido ou subdesenvolvido Este último caso, particularmente, consiste na realidade vivida pelo grupo de pesquisadores em questão.

Ao se buscar compreender os aspectos que levam a esta realidade tão singular, percebemos dois fatores principais: Um primeiro relativo ao processo de independência nacional bem mais tardio (1975), no mesmo contexto de vários outros países africanos, e todo o "delay" espaço-temporal que isto provoca no que tange a inserção de Moçambique na Divisão Internacional do Trabalho; E um segundo ligado a incorporação do aproveitamento do solo / uso tradicional da terra, enquanto dispositivo legal na Lei Nacional de Terras (1997), que, ao menos de modo formal, dá primazia ao uso em certo detrimento da troca.

Outro elemento fundamental, que vai desenhar a realidade geográfica do lugar de pesquisa foi a chamada "Guerra dos 16 anos", que teve início em 1976, um ano após a independência nacional, e perdurou até o ano de 1992, quando o país foi marcado por reformas de cunho neoliberal, na esteira das transformações vividas no contexto mundial do processo geral da acumulação capitalista. Estes anos de conflito forçaram a intensa migração rural/urbana, tendo como destino sobretudo a capital do país Maputo. Essa migração, com grande contingente populacional se alocando na cidade, sem a devida instalação de plantas industriais, por exemplo, para absorvê-lo enquanto mão de obra no mercado formal, foi fator preponderante para configurar a paisagem singular de Maputo e seu entorno próximo (Distritos de conotação rural), fortemente marcada pela presença de práticas agrícolas/agrárias na cidade.

Essa realidade, apesar de todas as dificuldades advindas da inserção precária do país na Divisão Internacional do Trabalho, oferece dignidade às mulheres do território rural, na cidade de Maputo e seu entorno próximo. O provimento alimentar direto e mesmo de renda, por meio da venda dos alimentos por elas produzidos, junto aos seus entes familiares (filhas, filhos, companheiros), é o que tem garantido a 
sobrevivência e a reprodução da vida de extensa parcela da população. São mulheres que demonstraram orgulho de sua condição de produtoras de alimentos e provedoras da economia doméstica que proporcionava a produção das extensas famílias.

Ou seja, a apropriação e organização coletiva ainda não foram destruídas, podendo ser fortalecidas para o uso do território agrícola/agrário e turístico sob a base comunitária sob a qual grande parte já se encontram edificados. No entanto, é preciso, sobretudo, que haja um provimento por parte da esfera pública, tanto do próprio país, como de parcerias com outros países, numa relação Sul-Sul, que oferte condições infraestruturais e orçamentária para sua viabilização em escala mais ampliada, capaz de potencializar a geração de renda e, assim, a emancipação econômica de parcela significativa da população em questão.

\section{REFERÊNCIAS}

SOUZA, Marcelo Lopes de Souza. ABC do desenvolvimento urbano. 7ạ ed - Rio de Janeiro: Bertrand Brasil, 2013. 192p.

ARAÚJO, Manuel G. Mendes. Geografia dos Povoamentos - Uma análise dos assentamentos rurais e urbanos. Maputo: Livraria Universitária, 1997.

CATSOSSA, Lucas. Discursos e realidades do agronegócio: do PRODECER no cerrado brasileiro ao ProSAVANA no Corredor de Nacala, em Moçambique. Dissertação (Mestrado em Geografia) - Faculdade de Ciências Humanas, Universidade Federal da Grande Dourados/UFGD, 2017.

PORTO-GONÇALVES, Carlos Walter. Sustentando a Insustentabilidade: Comentários à Minuta Zero do documento base de negociação da Rio+20. Site "Ecodebate". Disponível em: http://www.ecodebate. com.br/2012/02/01/sustentando-ainsustentabilidade-comentarios-a-minuta- zero-do-documento-base-de-negociacao-da-rio20-artigo-de-carlos-walterportogoncalves/. Acesso em: 20 maio 2012.

UNAC. Plano estratégico 2011-2015, Maputo, 2010.

WATERHOUSE, Rachel; VIJFHUIZEN, C; LAURICIANO, Gil. Estratégias das mulheres, proveito dos homens: género, terra e recursos naturais em diferentes contextos rurais em Moçambique. Maputo, Moçambique: Núcleo de Estudos de Terra, Faculdade de Agronomia e Engenharia Florestal, UEM: ActionAid-Moçambique, 2001. 